\title{
Synchrotron X-ray Charge-Density Study of Coordination Polymer $\left[\mathrm{Mn}(\mathrm{HCOO})_{2}\left(\mathrm{H}_{2} \mathrm{O}\right)_{2}\right]_{\infty}$
}

\author{
R. D. Poulsen', M. R. V. Jorgensen ${ }^{1}$, J. Overgaard', F. K. Larsen', W. Morgenroth ${ }^{1,2}$, T. Graber ${ }^{3}$, Y. \\ Chen $^{3}$ and B.B. Iversen ${ }^{1}$
}

${ }^{1}$ Department of Chemistry, University of Aarhus, Langelandsgade 140, DK-8000 Aarhus, Denmark

${ }^{2}$ DESY/HASYLAB, Notkestraße 85, 22603 Hamburg

${ }^{3}$ ChemMatCARS beamline, University of Chicago, Advanced Photon Source, Argonne, IL 60439, USA

Coordination polymers $(\mathrm{CP})$ provide a very attractive route for crystal engineering of functional materials.[1] Unlike porous zeolite frameworks, the structural identities of the reactants are preserved in the crystal, and the molecular assembly of CPs is reminiscent of building with Lego blocks. The structure of the compound is shown in Figure 1. It is composed of Mn-atoms linked by formate groups and water molecules. There are two distinct metal sites; Mn1 which is octahedrally coordinated to six formate bridges and $\mathrm{Mn} 2$ which is octahedrally coordinated to two formate bridges and four water molecules. This gives a layered structure where the Mn1 is cross linked in the bc-plane. The Mn2 sites link the Mn1-planes together via formate bridges. The compound crystallizes in space group $\mathrm{p} 2 / \mathrm{c}$ with unit cell parameters of $8.8 \AA, 7.2 \AA, 9.6 \AA$ and $97.6^{\circ}$.

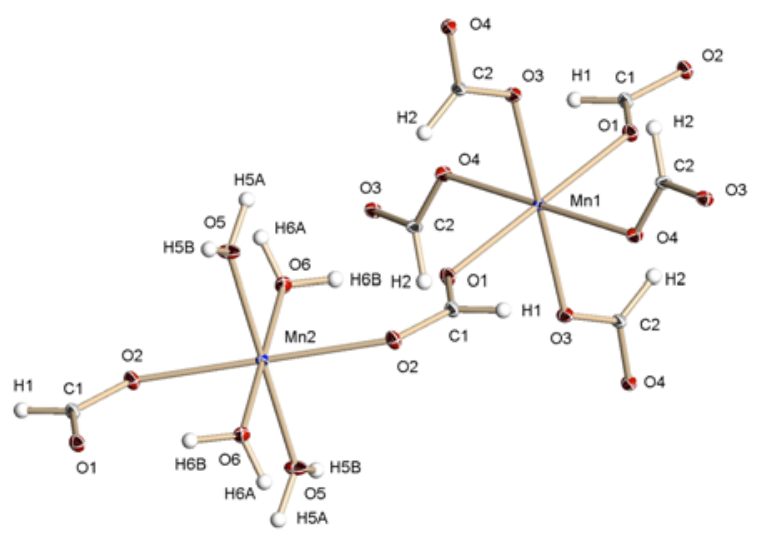

Figure 1: Structure of Manganese formate dihydrate at $16 \mathrm{~K}$ (Thermal ellipsoids shown at 50\% probability).

In this study, we have collected three high quality $\mathrm{x}$-ray diffraction data sets under very different conditions. The first is a conventional $100(2) \mathrm{K} \mathrm{MoK}_{\alpha}$ data set, the second is a $100(2) \mathrm{K}$ data set measured at D3, Hasylab and the third data set is measured at ChemMatCARS, APS at 16(2) K. The electron density is modelled for each of the three data sets using the Hansen-Coppens model.[2] The structures and electron densities obtained are very much alike and especially the two $100 \mathrm{~K}$ sets are almost identical. The data sets from D3 and the conventional source are the most precise, i.e. have the lowest uncertainties, but by comparing the electron density models with each other and high-quality theoretical calculation we find that the model obtained by the APS data is the most accurate. As the two $100 \mathrm{~K}$ models have almost identical features, we are lead to believe that the inaccuracy in the $100 \mathrm{~K}$ models is a thermal effect, especially thermal diffuse scattering. Static deformation density maps for selected ligand planes based on $16 \mathrm{~K}$ data are shown in Figure $2 \mathrm{~A}$ and $\mathrm{B}$.

The compound shows a very interesting magnetic ordering at low temperature. Polarized neutron diffraction has shown that the moments on the Mn1 and $\mathrm{Mn} 2$ are $0.38(2) \mu_{\mathrm{B}}$ and 1.73(2) $\mu_{\mathrm{B}}$ respectively. This study also shows that the ordering mechanism involves superexchange through the formate bridges.[3] These values are much lower than formal spin-only value of $5.92 \mu_{\mathrm{B}}$ for a high-spin $\mathrm{Mn}^{2+}$ ion. From magnetization measurements on a powdered sample, we estimate the effective magnetic moment to 5.840(2) $\mu_{\mathrm{B}}$ based on the Curie-Weiss law. 

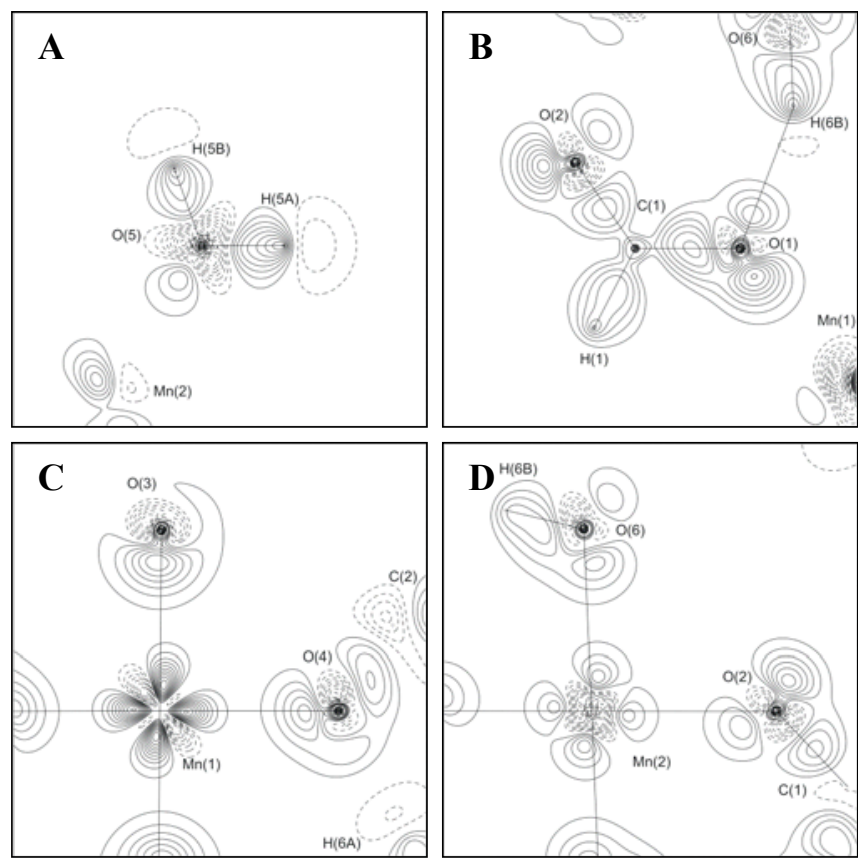

Figure 2: Static deformation density maps for selected planes. Contour interval is $0.1 \mathrm{e} \AA \mathrm{-}-3$, positive contours ate solid lines and negative contours are dashed lines. The zero contour is not shown.

From the obtained electron density model, based on the APS data, one can see some nonspherical features (See figure 2, C and D). High-spin $\mathrm{Mn}^{2+}$ is a spherical ion therefore the ions cannot merely be regarded as high-spin $\mathrm{Mn}^{2+}$. From the electron density one can derive the experimental $3 \mathrm{~d}$ orbital populations on the metal sites. The populations that minimize orbital cross terms are shown in Table 1. Here there is a clear difference in orbital population as expected from the model.

\begin{tabular}{cccccccc}
\hline & $\mathrm{d}\left(\mathrm{x}^{2}-\mathrm{y}^{2}\right)$ & $\mathrm{d}\left(\mathrm{z}^{2}\right)$ & $\mathrm{d}(\mathrm{xy})$ & $\mathrm{d}(\mathrm{yz})$ & $\mathrm{d}(\mathrm{xz})$ & $\mathrm{SUM}$ & $\begin{array}{c}\text { Max. } \\
\text { unpaired }\end{array}$ \\
\hline $\mathrm{Mn}(1)$ & 0.91 & 1.32 & 0.91 & 1.25 & 0.84 & 5.23 & 4.77 \\
& $(17.4)$ & $(25.2)$ & $(17.4)$ & $(23.9)$ & $(16.1)$ & & \\
$\operatorname{Mn}(2)$ & 0.89 & 1.37 & 0.89 & 1.26 & 0.92 & 5.32 & 4.68 \\
& $(16.7)$ & $(25.7)$ & $(16.8)$ & $(23.6)$ & $(17.3)$ & &
\end{tabular}

Table 1: Experimental d-orbital populations. The numbers in parentheses are percentages of the total number of d electrons. All values are given in local coordinate system found by minimizing orbital cross terms using the program ERD.[4]

The electron density model shows some degree of covalent interaction between ligand and metal sites as expected. Furthermore the model supports the ionic high-spin picture to a first approximation.

\section{References}

[1] a) S. Kitahawa; R. Kitaura; S. Noro, Angew. Chem Int. Ed., 43, 2334-2375 (2004); b) J. Y. Lu, Coord. Chem. Rev., 246, 327-347 (2003); c) M. Daoudi; D. Moler; H. Li; T. M. Reineke; M.

O’Keeffe; O. M. Yaghi, Acc. Chem. Res., 34, 319-330 (2001).

[2] N. K. Hansen; P. Coppens; Acta Cryst. A, 34, 909-921 (1978).

[3] P. Radhakrishna, B. Gillon, G. Chevrier, J. Phys. Condens. Matter, 5, 6447-6460 (1993).

[4] J. R. Sabino, P. Coppens, Acta Crystallogr. Sect. A , 59, 127-131 (2003). 